\title{
P57. Activation of RIG-I induces immunogenic cell death
}

\author{
S Bek*, D Kreppel, M Bscheider, CC Lin, T Haas, H Poeck \\ From 1st Immunotherapy of Cancer Conference (ITOC1) \\ Munich, Germany. 12-14 March 2014
}

\section{Background}

The interaction between the immune system and cancer cells has become a focus of recent cancer therapy research. Immunogenic cell death, short ICD, was described as a cell death modality that stimulates an immune response against dead-cell antigens, in particular when they derive from cancer cells. Most malignant cells are poorly immunogenic and fail to elicit an effective antitumour immune response. Certain anti-cancer treatments, however, have been shown to induce ICD and transform cancer cells into potent inducers of an anti-cancer immune response. An important component is the induction of a specific cytotoxic T-cell response driven by DCs that have engulfed and processed tumour antigens. Recently, we have shown that the RIG-I ligand 3pRNA induces tumosr cell death in vitro and in vivo. Whether and how 3pRNA induced tumour cell death leads to a specific antitumor response is unknown. Here we analyse the immunogenicity of RIG-I induced tumour cell death in vitro and in vivo.

\section{Material and methods}

We induced tumour cell death by treating ovalbumin expressing B16 melanoma cells with 3pRNA. We cocultured 3pRNA treated B16-OVA cells with splenic DCs and CFSE-labeled OT-I T-cells to analyse a specific T-cell activation and proliferation. Furthermore, we vaccinated 3pRNA treated B16-OVA cells subcutaneously into C57BL/6 mice to analyse their immunogenic potential in vivo. After vaccination, draining lymph node cells are analysed for $\mathrm{T}$-cell activation and IFNg production using flow cytometry.

\section{Results}

We show that 3pRNA treatment leads to increased cytokine expression, upregulation of costimulatory molecules, cross-presentation and induction of cell death in B16OVA melanoma cells in vitro. 3p-RNA treated B16-OVA cells induce proliferation and IFNg production of OT-I T-cells in co-cultures with spleen derived DCs. After subcutaneous injection of 3pRNA killed B16-OVA cells but not live B16-OVA cells into C57BL/6 mice, potent proliferation and IFNg production of antigen specific CD4 and $\mathrm{CD} 8 \mathrm{~T}$ cells is seen in the draining lymph node. Overall, these effects were more pronounced after 3pRNA treatment than after Oxaliplatin induced cell death.

\section{Conclusions}

3pRNA treatment of tumor cells leads to a potent immunogenic phenotype with induction of antigen-specific T-cell responses both in vitro and in vivo. These findings may have implications for a new therapeutic approach in immune mediated cancer treatment.

Published: 12 March 2014

doi:10.1186/2051-1426-2-S2-P31

Cite this article as: Bek et al:: P57. Activation of RIG-I induces

immunogenic cell death. Journal for ImmunoTherapy of Cancer 2014 2(Suppl 2):P31.

Submit your next manuscript to BioMed Central and take full advantage of:

- Convenient online submission

- Thorough peer review

- No space constraints or color figure charges

- Immediate publication on acceptance

- Inclusion in PubMed, CAS, Scopus and Google Scholar

- Research which is freely available for redistribution 